\title{
Knowledge of Causes, Management and Prevention of Childhood Diarrhoea among Nursing Mothers in Two Selected Primary Health Centers in Oyo State, Nigeria
}

\author{
Olaniyi A.A.O, Oyerinde O
}

\begin{abstract}
Diarrhoea is widely recognized as a major cause of childhood morbidity and mortality in many developing countries, particularly in sub-Saharan Africa. The objective of this study is to assess the knowledge of causes, management and prevention of diarrhoea among nursing mothers of under-two children in two selected primary health centers in Ibadan North Local Government, Oyo state. A descriptive non-experimental research design was used for the study. One hundred and sixty nursing mothers were selected from the two primary health centers. A structured self-administered questionnaire was used to collect data from participants while descriptive statistics of frequencies and percentages were used to analyze the data on the objectives.The study findings revealed that majority $(\mathbf{8 9 . 4 \%})$ of respondents have heard of diarrhoea before, many of them $(45 \%)$ had it from health centers and $(10.6 \%)$ from past experience of diarrhoea occurrence. Majority (78.1\%) of respondents had knowledge of diarrhoea, having been able to define what diarrhoea is in their own perspective and were able to identify some causes of diarrhoea. Over half $(63.8 \%)$ of them claimed their index child had diarrhoea out of which less than half $(38.8 \%)$ of them managed it with ORS. Less than half of them $(34.4 \%)$ managed the occurrence at home while $(25.5 \%)$ took their children to health center. In conclusion, mothers had knowledge of diarrhoea, but knowledge translation to prevention action was very poor. It is recommended that, health education of mothers on prevention should be intensified while mass media should assist in disseminating health information on diarrhoea prevention. Government should provide vaccine against rotavirus which should be included in the routine immunization schedule.
\end{abstract}

Index Terms: childhood diarrhoea; knowledge; prevention

\section{INTRODUCTION}

Diarrhoea is a common symptom of gastrointestinal infections caused by a wide range of pathogens, including bacteria, viruses and protozoa. However, just a handful of organisms are responsible for most acute cases of childhood diarrhoea. Rotavirus is responsible for more than $40 \%$ of all diarrhoea- related hospital admissions of children under-five [1].

Diarrhoea disease poses a major health problem in most developing countries of the world; it is associated with overcrowded settlement, poor access to clean water and good sanitation. It is estimated to have killed about three million children below the age of five annually [2].

Adenike Olaniyi, School of Nursing, U.C.H, Ibadan.Nigeria.

Opeyemi Oyerinde, School of Nursing, U.C.H Ibadan. Nigeria
It is an important cause of morbidity and mortality in this environment, conceivable because of the unsanitary conditions to which young children are exposed to and the fact that children are more vulnerable than adults. Diarrhoea disease is one of the leading causes of infant and child mortality in Nigeria, where it accounts for an estimated 250,000 deaths per annum [3].

Diarrhoea is an increase in stool mass, stool frequency or stool fluidity [4]. The study of diarrhoea disease among children is particularly important because diarrhoea results in electrolyte imbalance, malnutrition resulting from repeated attacks and most importantly death due to dehydration [4]. Infants and children at risk of diarrhea are majority from socio-economically deprived group inhabiting low income areas and suburb where little basic amenities are available [5]. Diarrhoea is commonly associated with teething and a variety of potential causes range from change in diet to bacteria from an object the baby put in his mouth to increased drooling from the teeth [6].

Diarrhoea is the second leading killer of children under the age of five, accounting for approximately $15 \%$ of under five child deaths world-wide, or almost two million deaths annually [2]. In 2004, diarrhoea disease was the leading cause of death in low-income countries, causing $69 \%$ of deaths overall in children under five years old, diarrhoea is the second leading cause of death, second only to pneumonia. Out of the 1.5 million children killed by diarrhoea disease in 2004, 80\% were under two years old [7].

In developing countries, children less than three years old experienced in average three episodes of diarrhoea every year. Each episode deprives the children of the nutrition necessary for growth. As a result, diarrhoea is a major cause of malnutrition and malnourished children are more likely to fall ill from diarrhoea [7].

\section{STATEMENT OF PROBLEM}

Diarrhoea causes rapid depletion of water and sodium, both of which are necessary for life. It is a common disease and one of the major determinants of childhood morbidity and mortality in Nigeria [8]. Mothers' knowledge about diarrhoea most times depends on various factors such as educational status, previous experience of managing the disease and the environment they live, in some cases. This study aimed at assessing the knowledge of diarrhoea, its management and prevention among mothers of under 
two years old. It is believed that the findings of this study will be of great importance in establishing intervention programme focusing on diarrhoea prevention and management, shifting attention and education of mothers to management and prevention of diarrhoea since knowledge of mothers on diarrhoea may have declined, thereby reducing the problem of mortality and morbidity among children and also help to improve general health care of children.

\section{SignifiCANCE OF THE STUDY}

This study will improve the level of awareness of mothers towards the prevention of diarrhoea among children thereby reducing the prevalence of diarrhoea among children. It will serve as a reference material for health workers especially nurses in intensifying mothers' education on the prevention of diarrhoea and adopt cost effective behavior in order to reduce childhood morbidity and mortality.

\section{OBJECTIVES}

To assess the knowledge of diarrhoea among nursing mothers in two selected Primary Health Centre in Oyo State of Nigeria

To assess their perceived knowledge of causes and management of diarrhoea in childhood

To assess their knowledge of prevention of childhood diarrhoea

\section{Methodology}

\section{A. Research Design:}

The study was a descriptive non-experimental study aimed to assess the knowledge of cause, management and prevention of diarrhoea in children among nursing mothers in Idi-ogungun Health Centre and Apata-Agbowo Primary Health Centre in Ibadan North Local Government Area of Ibadan, Oyo State, Nigeria.

\section{B. Research Setting:}

The research settings for this study are Idi-Ogungun Health Centre and Apata-Agbowo Health Centre of Ibadan North Local Government Area of Ibadan, Oyo state Nigeria.

\section{Sample and Sampling Technique}

All wards in Ibadan North Local Government were clustered into four and two wards were randomly selected; thereafter two primary health centers were randomly selected from the two wards. A convenient sample technique was used to select one hundred and sixty (160) nursing mothers from the two primary health centers. All consecutive mothers who came to the clinic with at least an under 2 year old child within the period of data collection ( 2 months) were recruited until the desired number was attained.

\section{Method of data analysis}

Data was collected using a structured self-administered questionnaire. All completed question- naires were analyzed and the results were represented in percentages, tables and frequencies, using a descriptive statistical technique.

\section{E. Ethical Consideration}

Permission was obtained from the office of the Local Government Health Authority to administer the questionnaires. The respondents were adequately informed about the study and verbal consent was obtained before administering the questionnaires. Strict confidentiality of the respondents' identities were maintained.

\section{DATA ANALYSIS}

Table I: Demographic data of respondents.

\begin{tabular}{|l|l|l|}
\hline Characteristics & $\mathrm{N}$ & $\%$ \\
\hline Ages of mothers (Year) & & \\
\hline $16-20$ & 15 & 9.4 \\
\hline $21-25$ & 44 & 27.5 \\
\hline $26-30$ & 65 & 40.6 \\
\hline 31 and above & 36 & 22.5 \\
\hline Level of Education & & \\
\hline No education & 27 & 16.9 \\
\hline Educated & 133 & 83.1 \\
\hline Type of Family & & \\
\hline Monogamous & 135 & 84.4 \\
\hline Polygamous & 25 & 15.6 \\
\hline Occupation & & \\
\hline Traders & 74 & 46.3 \\
\hline Civil Servant & 86 & 53.8 \\
\hline Marital Status & & \\
\hline Ever married & 145 & 90.6 \\
\hline Never married & 15 & 9.4 \\
\hline & & \\
\hline
\end{tabular}

Majority of respondents, $65(40.6 \%)$ were between $26-30$ years, $44(27.5 \%)$ were between $21-25$ years $15(9.4 \%)$ of them were between 16-20years while 36 (22.5\%) were 31years and above. Out of 160 respondents, 27(16.9\%) had no formal education while $133(83.1 \%)$ were educated. Majority 145 (90.6) were ever married, 135(84.4\%) were from monogamy and 25(15.6\%) were from polygamy; out of which $86(53.8 \%)$ were civil servants and 74(46.3\%) were traders (Table 1).

Table II: Demographic Characteristics of the Index Child

\begin{tabular}{|l|l|l|}
\hline Characteristics & N & \% \\
\hline Age in months & & \\
\hline $0-6$ & 101 & 63.1 \\
\hline $7-12$ & 52 & 32.5 \\
\hline $13-18$ & 6 & 3.8 \\
\hline $19-24$ & 1 & .6 \\
\hline Sex & & \\
\hline Male & 65 & 40.6 \\
\hline Female & 95 & 59.4 \\
\hline
\end{tabular}

The above table shows the age of the index child in month. Majority 101(63.1\%) were between the ages 0-6 months, 52 $(32.5 \%)$ were between the ages 7-12 month, $6(3.8 \%)$ were between the ages $13-18$ months, and $1(0.6 \%)$ were between the ages 19-24 months, out of which $65(40.6 \%)$ of them were males and 95(59.4\%) were females (Table 2). 
Table III: Mothers' perceived knowledge of diarrhoea

\begin{tabular}{|l|l|l|}
\hline Characteristics & N & \% \\
\hline $\begin{array}{l}\text { Have you heard about } \\
\text { diarrhea before? }\end{array}$ & & \\
\hline Yes & 143 & 89.4 \\
\hline No & 17 & 10.6 \\
\hline Means of Information & 39 & \\
\hline Friends & 72 & 24.4 \\
\hline Health center & 10 & 45 \\
\hline Mass media & 22 & 6.3 \\
\hline Parents & 17 & 13.8 \\
\hline Past experience & 10.6 \\
\hline $\begin{array}{l}\text { What do you understand by } \\
\text { the word diarrhoea? }\end{array}$ & & \\
\hline Blood in stool & 10 & 6.3 \\
\hline Increase in stool & 16 & 10.0 \\
\hline Increase in loose stool & 125 & 78.1 \\
\hline None & 9 & 5.6 \\
\hline
\end{tabular}

Majority of mothers 143(89.4\%) had heard about diarrhoea before while $17(10.6 \%)$ had not heard it before, out of which $39(24.4 \%)$ were informed about diarrhea from friends, $72(45 \%)$ heard it from health care center, 10(6.3\%) from mass media, 22(13.8\%) from their parents and $17(10.6 \%)$ from their past experience of diarrhoea in their infants, out of which majority $125(78.1 \%)$ of them were able to define diarrhoea as an increase in loose stool, 10(6.3\%) understood diarrhoea to be blood in stool, 16(10\%) understood it to be increase in stool (Table 3).

Table IV: Mothers'perceived knowledge of causes of diarrhoea

\begin{tabular}{|l|l|l|}
\hline Characteristics & Yes (\%) & No (\%) \\
\hline $\begin{array}{l}\text { Do you think } \\
\text { diarrhoea have any } \\
\text { cause? }\end{array}$ & $123(76.9)$ & $37(23.1)$ \\
\hline $\begin{array}{l}\text { Perceived Cause of } \\
\text { Diarrhoea }\end{array}$ & $115(71.9)$ & $8(5.0)$ \\
\hline Infection & $117(73.1)$ & $6(3.8)$ \\
\hline Poor hygiene & $23(14.4)$ & $100(62.50)$ \\
\hline No cause & $78(48.8)$ & $45(28.1)$ \\
\hline Teething & $34(21.3)$ & $89(55.6)$ \\
\hline $\begin{array}{l}\text { Not breastfeeding up to } \\
6 \text { month }\end{array}$ & & \\
\hline
\end{tabular}

Majority of respondents $123(76.9 \%)$ believed that diarrhoea had a cause, out of which $117(73.1 \%)$ perceived that the major cause of diarrhoea was poor hygiene followed by $115(71.9 \%)$ who perceived infection as a cause of diarrhoea while less than half $23(14.4 \%)$ of respondents said diarrhoea had no cause. Over half $78(48.8 \%)$ of respondents identify teething and not breastfeeding up to six month 34 (21.3) as causes of diarrhoea (Table 4).
Table V: Methods used by the nursing mothers in managing/treating diarrhoea

\begin{tabular}{|l|l|l|}
\hline Characteristics & N & \% \\
\hline $\begin{array}{l}\text { Has your child had diarrhoea } \\
\text { before? }\end{array}$ & 102 & 63.8 \\
\hline Yes & 58 & 36.3 \\
\hline No & & \\
\hline What was the cause? & 58 & 36.3 \\
\hline Contaminated food & 7 & 4.4 \\
\hline Infection & 19 & 11.9 \\
\hline Poor hygiene & 7 & 4.4 \\
\hline Sickness & 34 & 21.3 \\
\hline Teething & & \\
\hline $\begin{array}{l}\text { How did you manage } \\
\text { diarrhoea? }\end{array}$ & 13 & 8.1 \\
\hline Stopped feeding & 18 & 11.3 \\
\hline Did nothing & 5 & 3.1 \\
\hline Used drugs & 62 & 38.8 \\
\hline Give ORT & 40 & 25.5 \\
\hline Where did you manage & 55 & 34.4 \\
\hline Health center & 3 & 1.9 \\
\hline Home & & \\
\hline Traditional homes & & \\
\hline
\end{tabular}

Majority of mothers $102(63.8 \%)$ claimed that their index child has had diarrhoea before, out of which $58(36.3 \%)$ said it was caused by contaminated food, $2(8.8 \%)$ did not know the cause, $7(4.4 \%)$ said infection, $19(11.9 \%)$ poor hygiene, $7(4.4 \%)$ sickness and $34(21.3 \%)$ said teething. Majority of respondents $62(38.8 \%)$ used ORT while less than half of them $13(8.1 \%)$ stopped feeding during diarrhoea, 18(11.3\%) did nothing and 5(3.1\%) used drugs. Many mothers $55(34.4 \%)$ managed their index child at home, 40(25.5\%) managed at the health center and $3(1.9 \%)$ at traditional homes (Table 5).

Table VI: Knowledge of prevention of diarrhoea

\begin{tabular}{|l|l|l|}
\hline & Yes $(\%)$ & No $(\%)$ \\
\hline $\begin{array}{l}\text { Is diarrhea in children } \\
\text { preventable? }\end{array}$ & $131(81.9)$ & $29(18.1)$ \\
\hline $\begin{array}{l}\text { Means of preventing } \\
\text { diarrhoea }\end{array}$ & & \\
\hline Handwashing & $118(73.8)$ & $1(0.6)$ \\
\hline Personal Hygiene & $116(72.5)$ & $3(1.9)$ \\
\hline Use of herbs & $20(12.5)$ & $99(61.9)$ \\
\hline Medication & $91(56.9)$ & $28(17.5)$ \\
\hline Immunization & $61(38.1)$ & $58(36.3)$ \\
\hline Exclusive breastfeeding & $103(64.4)$ & $16(10.0)$ \\
\hline $\begin{array}{l}\text { Avoid complementary feed } \\
\text { during teething }\end{array}$ & $49(30.6)$ & $69(43.1)$ \\
\hline
\end{tabular}

Majority of respondents $131(81.9 \%)$ agreed that diarrhoea is preventable, out of which $118(73.8 \%)$ of the respondents said diarrhoea can be prevented by hand washing, $116(72.5 \%)$ by personal hygiene, $20(12.5 \%)$ by use of herbs, $91(56.9 \%)$ by use of medications, $61(38.1 \%)$ by immunization, $103(64.4 \%)$ by exclusive breastfeeding, 
$49(30.6 \%)$ by avoiding complementary feed during teething (Table 6).

\section{DISCUSSION OF FINDINGS}

The findings from the study revealed that over half of respondents were between 26 -30 years, ever married, from a monogamy family, educated and had a means of livelihood. This implies that respondents were adult, mature enough to bear children and with a family that can care for children. Majority of them had at least primary school education because of the awareness from government that everyone must be educated and were economically empowered. This is similar to a study conducted in Odeda, Ogun State, it was revealed that majority of respondents were between 20-40 years, $79.1 \%$ were educated while $20.9 \%$ had no formal education [9]. But in contrast to this, was a study conducted in Nepal [10], where less than half $(30.8 \%)$ of respondents were between 31-35 years, majority $(72.3 \%)$ had no education but similar to the study was that, all respondents had a means of livelihood.

This study also revealed that majority of children brought to the health centre were between 0-6 month old and females. This implies that mothers adhere to the instructions of the health workers to always bring their children to the Infant Welfare Clinic for immunization and to monitor their growth pattern. This is in contrast to a study conducted in Tanzania [11], where majority of children used for the study were 2 years old and $46 \%$ were females.

This study also shows the mothers' perceived knowledge of diarrhoea, where majority of them had knowledge of diarrhoea in children and got the information from health centers. Majority of them were able to define diarrhoea in their own perspective. They were aware that diarrhoea has a cause and attributed the cause of diarrhoea to poor personal hygiene. This implies the significance of education on knowledge of the nursing mothers on diarrhoea and the fact that many of them attended the antenatal clinic during conception. Majority of them claimed that one of their children at one time or the other had diarrhoea while less than half of them claimed it was caused by contaminated food and treated the diarrhoea with Oral Rehydration Solution (ORS), out of which $25.5 \%$ said the diarrhoea was treated at the nearest Primary Health Center. This implies that despite the fact that many of them attended the clinic at one time or the other, with knowledge of diarrhoea, their children still had some episodes of diarrhoea, which they were able to identify the cause and was duly treated. It also implies that the health education on the use of ORS as part of the treatment for diarrhoea given to thesemothers at the clinic and other sources of their information were adequately practiced. This is similar to the study conducted in Odeda [9], where all mothers in the study had knowledge of diarrhoea, $88.7 \%$ got the knowledge information from the clinic and $62.6 \%$ knew that diarrhoea is caused by germs, a few $(15.7 \%)$ indicated that it is caused by teething out of which over half $(57.4 \%)$ of them had experienced it with their children at one time or the other. It is also similar to the study conducted in Nepal [10], where majority of mothers claimed that the occurrence of diarrhoea in children was preventable through preventive approach such as maintaining cleanliness and making a habit of hand washing before feeding the child. They also preferred ORS solution, salt sugar water solution and salted soft loose rice for use during episode of diarrhoea in their children. Also similar to the study conducted in Sunsari, Nepal [12], it was shown that majority $(97.6 \%)$ of the mother had information about ORS and its usefulness in the management of dehydration as a result of diarrhoea.

This study also showed that $81.9 \%$ of respondents believed that diarrhoea in children can be prevented out of which $73.8 \%$ and $72.5 \%$ said diarrhoea can be prevented through proper hand washing and good personal hygiene respectively. This implies that respondents were educated on good and proper child care practices during their visit to the clinics. This study is in contrast to another study [13], where $46.8 \%$ of diarrhoea episode were treated with antimicrobial agents and $28.5 \%$ were not treated at all by the nursing mothers. This is similar to the present study where $11.3 \%$ of respondents did not treat their children during the episode of diarrhoea.

In the study conducted in Odeda Local Government of Ogun State [9], it was revealed that majority (93\%) of mothers preferred to manage diarrhoea at home while $78.3 \%$ will prefer to buy and administer drugs and use ORS without visiting the clinic out of which $43.5 \%$ will administer antibiotics, $29.6 \%$ will use herbs only and $14.7 \%$ will use doctor's prescription. This is similar to the present study, where respondents managed the episode of diarrhoea in their children at home while some others preferred their children to be managed at the health centers and $3.1 \%$ of them used drugs to manage the disease.

\section{CONCLUSION}

From the result of this study, it was seen that nursing mothers had knowledge of diarrhoea having being informed basically by health workers in the hospital and attributed the major cause of it to infection, poor hygiene and teething. Most respodents were able to identify different causes of diarrhoea and this influenced their ability to manage it mostly at home but their knowledge of management was still poor because despite the fact that they had knowledge of what diarrhoea is, many of their children still had episode/s of diarrhoea, although they were able to identify some of the causes that led to the occurrence. Since they were able to identify some causes of these occurrences, there is need to improve their knowledge of prevention.

\section{RECOMMENDATIONS}

Reducing childhood diarrhoea requires interventions to make children healthier and less likely to develop infections that lead to diarrhoea; clean environments that are less likely to transmit disease; and the support of communities and caregivers in consistently reinforcing healthy behaviours and practices over time [1]. Health education on diarrhoea should not only be what is all about, but ways to prevent the occurrence, since prevention is better than cure.

Therefore, it is recommended that health educating child bearing mothers should be highly intensified, especially good 
hygiene practices and hand washing with soap which are some of the effective ways in preventing childhood diarrhoea. Organizing an interventional programmes that will focus on diarrhoea prevention and management and programmes that will discourage the indiscriminate use of antibiotics and herbal mixture. Apart from health workers educating mothers/caregivers on prevention, mass media can assist in dissemination of health information through public enlightenment regarding prevention of childhood diarrhoea like proper hand washing with soap, encourage mothers on exclusive breastfeeding, adequate sanitation and good personal and environmental hygiene which are cost-effective interventions for reducing childhood death from diarrhoea. This will serve as a constant reminder of the consequences of wrong child health decisions. Government should intensify their effort in making sure that people have access to clean water and encourage childhood immunization against rotavirus/measles that is responsible for diarrhoea and also fund any infant health programmes in collaboration with other Non-governmental Organization

\section{REFERENCES}

[1] United Nations Children's Education Fund. (2009). Diarrhea: why children are still dying and what can be done. Available from: http://www.7pointplan.org/global-burden-childhooddiarrhea.html

[2] United Nations Children's Fund. (2003). Reports on the State of the World's Children. UNICEF, New York.

[3] B.F. Iyun and E.A. Oke, "Ecological and Cultural barriers to treatment of childhood diarrhoea in riverine areas of Ondo State, Nigeria". Social Science \& Medicine (50): 2000. 953-964.

[4] R.S. Cotran, V. Kumar and T.W.B. Collins, "Robbins Pathologic Basis of Diseases". 6th Ed. USA Saunders Co. 1999. 805 -810.

[5] O. Ogbu, N. Agumadu,C.J. Uneke and E.S. Amadi, "Aetiology of acute infantile diarrhoea in the south -eastern Nigeria : An assessment of microbiological and antibiotic sensitivity profile". The Internet Journal of Third World Medicine, Vol .7, 2008. (1)

[6] M.L. Macknin, M.Piedmonte, J. Jacobs and C. Skibinski (2010). "Symptoms associated with Infant teething: a prospective study". Pediatrics. 2010;105:747-752.

[7] World Health Organization. (Accessed December 31, 2009). Assessing vaccine-preventable diseases burden and immunization impact.

Geneva: http://www.who.int/immunization_monitoring/burden/en/.

[8] S.A. Alabi, R.A Audu and K.S Ouedeji, "Bacteria and Parasitic Agents Associated With Infantile Diarrhea In Lagos”. Nig J Med Res; Vol. 2: 1998. 29-32.

[9] C.A. Agbon, E.C. Okeke and I.M. Olawale, "Diarrhoea Management Practices by Mothers of Odeda Local Government Area, Ogun State". JHER Vol.13, 2010. pp. 58-64.

[10] M. Ansari, I. Mohamed and S. Ravi, "A survey of mothers' knowledge about childhood diarrhoea and its management among a marginalized community of Morang, Nepal", Australas Medical Journal. 4(9): 2011 474-479.

[11] K.D. Mwambete and R. Joseph, "Knowledge and perception of mothers and caregivers on childhood diarrhoea and its management in Temeke Municipality, Tanzania". Tanzania Journal of Health Research Volume 12, 2010. No 1.

[12] J. Nilambar, S. Rupa and B. Dharinadhar, "Knowledge, attitude and practices of mothers regarding home management of acute diarrhoea in Sunsari, Nepal".2006. PubMed.

[13] O.O. See comment in PubMed Commons belowOmotade, A,A Adeyemo, C.M. Kayode and O. Oladepo, "Treatment of childhood diarrhoea in Nigeria: need for adaptation of health policy and programmes to cultural norms". ournal of Health Population and Nutrition.;18(3): 2000. 139-44. 